\title{
Recurrence of Ischemic Stroke Patients with Common Risk Factors
}

\author{
DEY SK ${ }^{1}$, BAKSHI L ${ }^{2}$, AHMED A $^{3}$, SHAHIDULLAH M ${ }^{4}$, HABIB A $^{5}$, CHOWDHURY A $^{6}$, ISLAM MR ${ }^{7}$
}

\begin{abstract}
:
Background: Mortality and morbidity due to recurrent ischemic stroke is gradually increasing in Bangladesh due to gradual increase of life expectancy. Previously many studies were done to identify the risk factors of ischemic stroke. But there was scanty data about risk factors of recurrent ischemic stroke. So, it is time demanding to find out those risk factors for ischemic stroke recurrence to reduce the mortality and morbidity from recurrent ischemic stroke. The objective of the study was to determine the frequency of recurrence ischemic stroke events within one year of follow up after discharge from hospital admitted due to first ever stroke. Methods: This is a prospective cohort study. This study was conducted on 150 patients admitted in Neurology ward of BSMMU, presenting with first ever ischemic stroke. Patients $m R S$ were evaluated three monthly interval for one year. Sudden onset $m R S$ deterioration than previous one during this one year period was categorized as recurrence. Results: Stroke recurrence was found in 30 patients including 8 patients who died due to stroke recurrence. the most frequent age group was $>75$ years representing $44.4 \%$ who developed recurrence of stroke The cumulative risk of recurrence rate was $14.7 \%$ at three months, $15.3 \%$ at six months, $17.3 \%$ at ninth months, $20 \%$ at one year. Old age, Male sex, Hypertension, DM and dyslipidemia were the most common risk factors among recurrent stroke patients. Conclusion: It was concluded that in hospital admitted patients of first ever stroke, recurrence events was more in patients of older male patients with multiple risk factors. First three months was the worst period for recurrence after index stroke.
\end{abstract}

Key words: stroke, recurrence, risk factors etc.

Introduction:

Among stroke incidence and prevalence of ischemic stroke is quite high. So disability due to ischemic stroke has a greatimpact on public health in any country. In our country life expectancy gradually increasing, so incidenceof ischemic stroke and stroke recurrence is also gradually increases in population. The etiopathogenesis of stroke is multifactorial. Multiple modifiable and nonmodifiable risk factors being associated. Nonmodifiable risk factors for stroke include older age, male gender, ethnicity, family history, and prior history of stroke. Modifiable risk factors include arterial hypertension, DM, dyslipidemia, heart disease, and carotid artery disease. Lifestyle factors include lack of physical activity, cigarette consumption, alcohol abuse etc. Less welldocumented risk factors include blood markers (e.g., C-reactive protein), ankle-brachial blood pressure ratios, silent cerebral infarcts, whitematter hyperintensities on magnetic resonance imaging (MRI), and degree of carotid artery intimamedia thickness. Findings from the INTERSTROKE study suggest that hypertension, current smoking, high waist-to-hip ratio, sedentary lifestyle, diabetes mellitus, alcohol intake,

1. Dr. Subash kanti Dey Associate professor, Department of Neurology, BSMMU, Dhaka, Bangladesh.

2. Dr. Lipy Bakshi, Assistant professor, Department of Gynae \&Obs, Dhaka National Medical college, Dhaka, Bangladesh.

3. Dr. Anis ahmed, Assistant professor, Department of Neurology, BSMMU, Dhaka, Bangladesh.

4. Dr. Md. Shahidullah, Associate professor, Department of Neurology, BSMMU, Dhaka, Bangladesh.

5. Dr. Ahsan Habib , Associate professor, Department of Neurology, BSMMU, Dhaka, Bangladesh.

6. Dr. Ashish Chowdhury, Resident, Neurology, Department of Neurology, BSMMU, Dhaka, Bangladesh.

7. Prof. Dr. Md. Rafiqul Islam, Chairman and Professor, Department of Neurology, BSMMU, Dhaka, Bangladesh. 
psychosocial stress and depression, cardiac causes and ratio of apolipoproteins $B$ to $A 1$ account for about $90 \%$ risk of stroke ${ }^{1}$. Hypertension (63\%) was the main risk factor for stroke,followed by heart disease (24\%), diabetes mellitus (DM) (21\%), and hyperlipidaemia (7\%). A study done within 400 hospitalized stroke patients in Dhaka medical college Hospital from July to December 2007 revealed $56 \cdot 25 \%$ patients had cerebral infraction. The risk factors present in the stroke cases included hypertension (58.62\%) cigarette smoking $(53.79 \%)$, lipid disorder (48.01\%), heart diseases (25.75\%), DM (20.01\%), and previous history of stroke $(10 \cdot 61 \%)^{2}$. In another study, the risk factors for stroke were investigated in 85 young patients (aged 14 to 45 years) hospitalized at the $\mathrm{DMCH}$ between January 2008 and July 2009. ${ }^{3}$ The majority $(61 \cdot 18 \%)$ suffered from an Ishemic stroke. The common risk factors were hypertension (60.00\%), hypercholesterolaemia $(38.80 \%)$, diabetes $(35.20 \%)$, smoking $(32.90 \%)$, premature atherosclerosis $(8 \cdot 20 \%)$, and oral contraceptive use $(3.8 \%)$.

Stroke recurrence after initial stroke vary widely in different studies from 3 to $22 \%$ in one year ${ }^{4,15}$. Recurrent stroke was defined as a new cerebrovascular event that met one of the following criteriaa $^{7,12}$. (1) If new neurological deficit that was clearly different from that of the index stroke, (2) if neurological deficit follow anatomical area other than index case (3) if new deficit follow stroke subtype different from that of the index stroke. Systemic causes of clinical deterioration after an initial stroke (eg, hypoxia, hypotension, hyperglycemia, infection) may worsening symptoms of index cases during follow up ${ }^{16}$. It must be excluded before diagnosis of recurrence event. There was no definition of early recurrence, In this study if recurrence within three months after index stroke diagnosed as early recurrence and a similar criterion had been used by other studies of early recurrence ${ }^{17,18}$.

Many studies were done for modifiable and nonmodifiable risk factors for ischemic stroke. But there was scanty data in home and abroad about risk factors for recurrent stroke. No consensus yet exists about contribution of risk factors for recurrent stroke. This study showed the effect of widely accepted stroke risk factors on recurrent stroke after first-ever ischemic infarction.

\section{Methods:}

This study was done on the first ever ischemic stroke patients admitted in the inpatient Neurology Department of BSMMU. Total 162 patients were selected for study, but due to cognitive impairment after stroke seven patients were excluded, another five patients were excluded from the study due to non-co-operative in three monthly follow up. So total 150 patients were analyzed for recurrence three months interval up to one year.All patients give follow up for recurrence by measuring $\mathrm{mRS}$ scale comparing with the previous status. Deterioration of any index case mRS scale than previous was recorded as recurrence.

\section{Results :}

Table-I

Distribution of the patients according to age

\begin{tabular}{|c|c|c|c|}
\hline \multirow[t]{2}{*}{ Age (Years) } & \multirow[t]{2}{*}{$\mathrm{n}$} & \multicolumn{2}{|c|}{ Recurrence } \\
\hline & & Yes & No \\
\hline$\leq 45$ & 15 & $0(.0)$ & $15(100.0)$ \\
\hline $46-55$ & 35 & $6(17.1)$ & $29(82.9)$ \\
\hline $56-65$ & 51 & $11(21.6)$ & $40(78.4)$ \\
\hline $66-75$ & 40 & $9(22.5)$ & $31(77.5)$ \\
\hline$>75$ & 9 & $4(44.4)$ & $5(55.6)$ \\
\hline Total & 150 & $30(20.0)$ & $120(80.0)$ \\
\hline Mean $\pm S D$ & & $64.80 \pm 9.48$ & $60.04 \pm 11.120 .033^{a}$ \\
\hline
\end{tabular}

Table I shows that the most frequent age group was $>75$ years representing $44.4 \%$ who developed recurrence of stroke but $55.6 \%$ was not developed. But most of the ischemic stroke patients were 5665 years group among them $21.6 \%$ patients developed recurrence.

Table-II

Distribution of the patients according to sex by recurrence

\begin{tabular}{lcccr}
\hline Sex & $n$ & \multicolumn{2}{c}{ Recurrence } & p value \\
\cline { 3 - 4 } & & Yes & No & \\
\hline Male & 80 & $17(21.2)$ & $63(78.8)$ & $0.682^{a}$ \\
Female & 70 & $13(18.6)$ & $57(81.4)$ & \\
\hline Total & 150 & $30(20.0)$ & $120(80.0)$ & \\
\hline
\end{tabular}

Table II showed male patient developed more recurrence. 
Table-III

Distribution of the patients according to co-morbidity/risk factors by age

\begin{tabular}{|c|c|c|c|c|c|c|c|}
\hline \multirow{2}{*}{$\begin{array}{l}\text { Co-morbidity / } \\
\text { risk factors }\end{array}$} & \multirow[t]{2}{*}{$n$} & \multicolumn{5}{|c|}{ Age (years) } & \multirow[t]{2}{*}{$p$ value } \\
\hline & & $\leq 45$ & $46-55$ & $56-65$ & $66-75$ & $>75$ & \\
\hline \multicolumn{8}{|l|}{ HTN } \\
\hline - Yes & 106 & $8(7.5)$ & $25(23.6)$ & $36(34.0)$ & 32 (30.2) & $5(4.7)$ & $0.302^{\mathrm{a}}$ \\
\hline - $\quad$ No & 44 & 7 (15.9) & $10(22.7)$ & $15(34.1)$ & $8(18.2)$ & $4(9.1)$ & \\
\hline \multicolumn{8}{|c|}{ 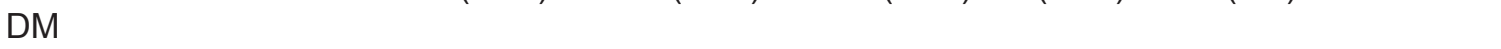 } \\
\hline - Yes & 75 & $5(6.7)$ & $23(30.7)$ & $28(37.3)$ & 14 (18.7) & $5(6.7)$ & $0.053^{a}$ \\
\hline - $\quad$ No & 75 & $10(13.3)$ & $12(16.0)$ & $23(30.7)$ & $26(34.7)$ & $4(5.3)$ & \\
\hline \multicolumn{8}{|l|}{ Smoking } \\
\hline - Yes & 37 & $2(5.4)$ & $9(24.3)$ & $15(40.5)$ & $8(21.6)$ & $3(8.1)$ & $0.643^{a}$ \\
\hline - $\quad$ No & 113 & $13(11.5)$ & $26(23.0)$ & 36 (31.9) & $32(28.3)$ & $6(5.3)$ & \\
\hline \multicolumn{8}{|l|}{ Dyslipidaemia } \\
\hline - Yes & 69 & $4(5.8)$ & $19(27.5)$ & $23(33.3)$ & $19(27.5)$ & $4(5.8)$ & $0.511^{a}$ \\
\hline - $\quad$ No & 81 & $11(13.6)$ & $16(19.8)$ & $28(34.6)$ & $21(25.9)$ & $5(6.2)$ & \\
\hline \multicolumn{8}{|l|}{ Family history } \\
\hline - Yes & 39 & $5(12.8)$ & $13(33.3)$ & $10(25.6)$ & $10(25.6)$ & $1(2.6)$ & $0.306^{a}$ \\
\hline - $\quad$ No & 111 & $10(9.0)$ & $22(19.8)$ & $41(36.9)$ & $30(27.0)$ & $8(7.2)$ & \\
\hline \multicolumn{8}{|c|}{ (1) } \\
\hline - Yes & 25 & $1(4.0)$ & $6(24.0)$ & $12(48.0)$ & $2(8.0)$ & $4(16.0)$ & $0.019^{a}$ \\
\hline - $\quad$ No & 125 & $14(11.2)$ & $29(23.2)$ & 39 (31.2) & $38(30.4)$ & $5(4.0)$ & \\
\hline
\end{tabular}

Table-IV

Distribution of the patients according to co-morbidity/risk factors by recurrence

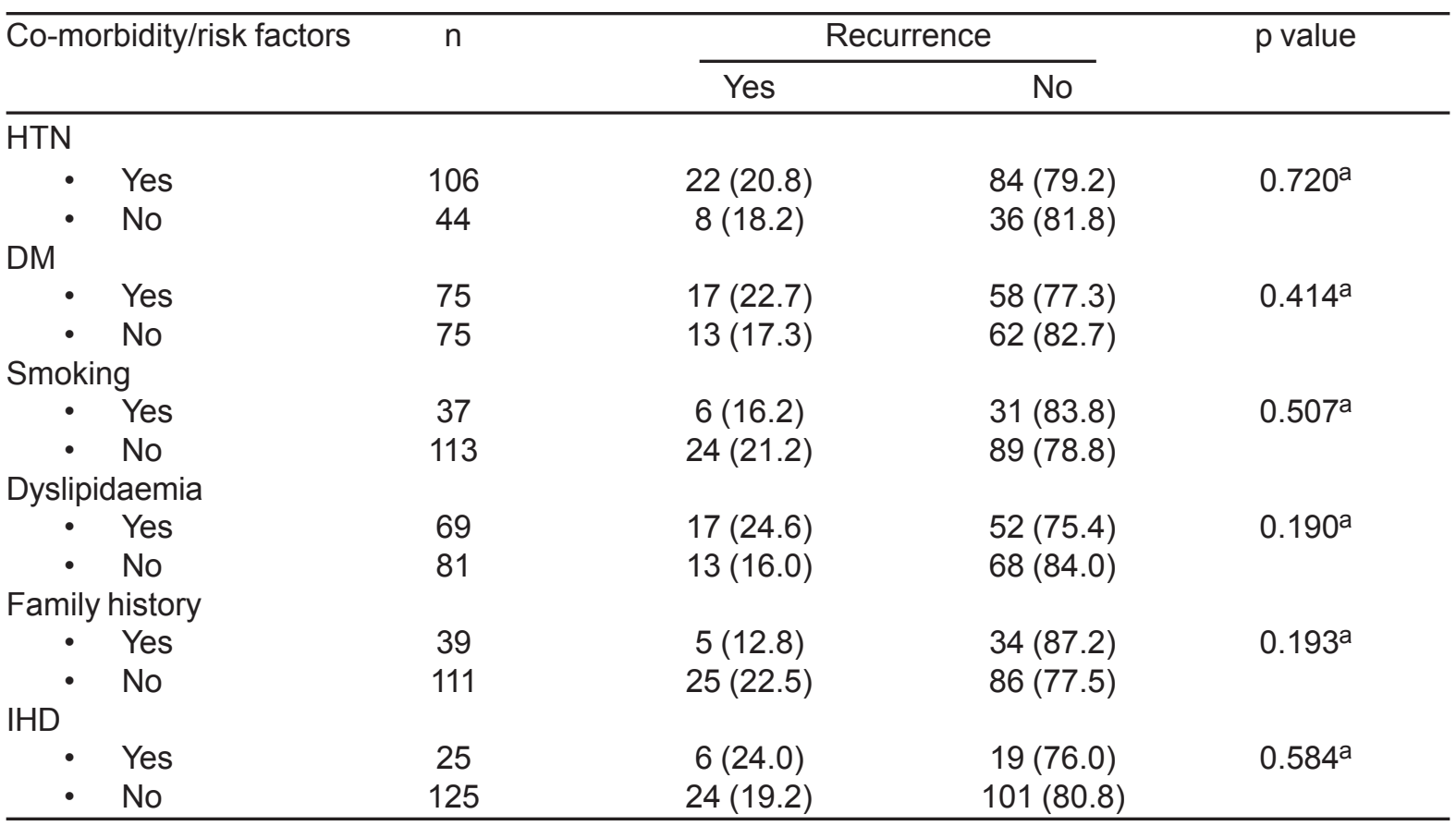

Table IV showedindex stroke patients who were hypertensive, diabetic and dyslipidemic had increased incidence of recurrence, though it was not statistically significant. 
Table-V

Distribution of the patients according to multiple risk factors by recurrence

\begin{tabular}{llccl}
\hline Multiple risk factors & $\mathrm{n}$ & \multicolumn{2}{c}{ Recurrence } & p value \\
\cline { 3 - 4 } & & Yes & No & \\
\hline No risk factor & 15 & $1(6.7)$ & $14(93.3)$ & $0.305^{\mathrm{b}}$ \\
One risk factor & 30 & $5(16.7)$ & $25(83.3)$ & $0.610^{\mathrm{a}}$ \\
Two risk factors & 37 & $11(29.7)$ & $26(70.3)$ & $0.088^{\mathrm{a}}$ \\
Three risk factors & 30 & $7(23.3)$ & $23(76.7)$ & $0.610^{\mathrm{a}}$ \\
Four risk factors & 27 & $5(18.5)$ & $22(81.5)$ & $0.832^{\mathrm{a}}$ \\
Five risk factors & 11 & $1(9.1)$ & $10(90.9)$ & $0.694^{\mathrm{b}}$ \\
\hline
\end{tabular}

Table III showed most of the patient suffered from hypertension followed by DM and dyslipidemia but it was not statistically significant in any age group.

Combinations modifiable risk factors analysis showed no statistically significant contribution to recurrence of stroke.

Table-VI

Distribution of the patients according to recurrence

\begin{tabular}{lcc}
\hline Recurrence & Frequency & Percent \\
\hline Yes & 30 & 20.0 \\
No & 120 & 80.0 \\
\hline Total & 150 & 100.0 \\
\hline
\end{tabular}

Recurrence of ischemic stroke was $20 \%$ after one year follow up.

Table-VII

Distribution of the patients according to death

\begin{tabular}{lcc}
\hline Death & Frequency & Percent \\
\hline Yes & 8 & 5.3 \\
No & 142 & 94.7 \\
\hline Total & 150 & 100.0 \\
\hline
\end{tabular}

Case Fatality Rate $=26.7 \%$

Table-VIII

Distribution of the patients according to cumulative recurrence

\begin{tabular}{lcc}
\hline Recurrence & Frequency & Percent \\
\hline Three months & 22 & 14.7 \\
Six months & 23 & 15.3 \\
Nine months & 26 & 17.3 \\
Twelve months & 30 & 20.0 \\
\hline
\end{tabular}

Most of the patients suffered from recurrence of stroke in first three months which was about $14 \%$. After one year it was $20 \%$.

\section{Discussion:}

In this study, stroke recurrence with multiple risk factors up to 1 year after initial ischemic stroke was estimated. The results showed that in one-year follow-up period, $20 \%$ of the patients had suffered from an ischemic stroke recurrence; moreover, $5.3 \%$ of patients died as a consequence of the recurrence. This study found that the cumulative risk of recurrence was $14.7 \%$ at 3 months, $15.3 \%$ at 6 months $17.3 \%$ at 9 months and $20 \%$ at 1 year.Recurrence of stroke within first three months in other studies was variable. In a Japanese study , they showed it was $4.9 \%{ }^{19}$. American heart association showed recurrence within 3 months was $7.4 \%{ }^{20}$. This study showed recurrence rate was higher than other studies. Most probably due to inclusion of more aged patients in this study.At one year the annual risk of stroke recurrence also variable in many studies, $13 \%$ the Oxfordshire Community Stroke Project ${ }^{21} 11.91 \%$ and $17.7 \%$ in china $.22,234 \%$ in perth, western Australia, ${ }^{24} 8 \%$ in south carolina 25 . This study showed it was $20 \%$ a little higher than other studies. In this study 8 patients $(5.3 \%$ ) died. Case fatality rate was $26.7 \%$ . one study showed case fatality rate was $31.8 \%$ 20 . This is also near similar to previous studies. The average age at stroke onset was $64.80 \pm 9.48$ years. Though most of the ischemic stroke patients were 56-65 years group, among them 21.6\% patients developed recurrence. Maximum patients who developed recurrence of stroke were $>75$ years age group which was $44.4 \%$. It was not statistically significant. $21.2 \%$ male patient was developed recurrence of stroke but $18.6 \%$ female patients were developed recurrence which was also not statistically significant. This male predominant recurrence of stroke was similar with the Framingham Study ${ }^{6}$ but not in other studies. ${ }^{15}$ The profile of the five modifiable selected 
risk factors at enrollment for these 150 stroke patients was analyzed. Only $15(10 \%)$ patients had none of the above five risk factors. Of the remaining, $30(20 \%)$ patients had only one risk factor, $37(24.66 \%)$ had two risk factors, $30(20 \%)$ had three risk factors, $27(18 \%)$ had four risk factors, and $11(7.33 \%)$ had all five risk factors. Most of the recurrent stroke patients has been suffering from two risk factors $(29.7 \%)$ patients (Hypertension and DM) . Maximum stroke patient $(74.9 \%)$ has been suffering from hypertension in this study. Previously one study showed hypertension (HTN) was associated with a higher risk of stroke recurrence ${ }^{6}$ same result also showed in the Lehigh Valley Study ${ }^{16}$ but it was not found in Chicago, Maryland, and Boston using the Stroke Data Bank, ${ }^{7} \mathrm{DM}$ was the second most common risk factors in this study. About $50 \%$ stroke patients has been suffering from DM. Similarly, patients with diabetes mellitus (DM) had an increased risk of stroke recurrence in several stroke cohorts studied by Hier et al, ${ }^{7}$ Alter et al, ${ }^{16}$ and Olsson et al ${ }^{15}$ but not by Viitanen et al ${ }^{14}$ or Broderick et $\mathrm{al}^{26}$.

Among 150 patients, Sixty nine patient ( $46 \%$ ) has been suffering from dyslipidemia. Among them 17 $(24.7 \%)$ has recurrence of stroke. One previous study showed dyslipidaemia in recurrent stroke patients was $56 \%{ }^{27}$. Inthis study 37 patients was smoker (24.66\%). Among them $16.2 \%$ patients had recurrence of stroke. One study showed $9.5 \%$ smoker developed recurrence of stroke ${ }^{28}$.

In this study 39 patients has history of stroke in first degree relatives. Among them $12.8 \%$ had recurrence. One study showed $6.2 \%$ had family history ${ }^{29}$. Among 150 index stroke patients 25 patients has arrythmia. Recurrent stroke events was occurred in $24 \%$ patients. One study showed arrthmia was present in only $5 \%$ patients who developed recurrence stroke within one year ${ }^{30}$. In the LVRSS Cox modeling analysis, of those cardiac conditions studied, only AF emerged as a significant predictor for stroke recurrence and $16 \%$ of patients was suffering from $\mathrm{AF}^{31}$.

\section{Conclusion:}

Older age with multiple risk factors were more vulnerable for recurrence of ischemic stroke. First three months were the worst time for recurrence after index stroke.
Acknowledgement:

The study was funded by the Bangabandhu Sheikh Mujib Medical University research grant.

\section{References:}

1. O'Donnell, M.J., Xavier, D., Liu, L., Zhang, H., Chin, S.L., Rao-Melacini, P., et al.; INTERSTROKE investigators. Risk factors for ischemic and intracerebralhaemorrhagic stroke in 22 countries (the INTERSTROKE study): a case-control study. Lancet, 2010 ;376 : 112-23.

2. Hossain, A.M., Ahmed, N.U., Rahman, M., Islam, M.R., Sadhya, G. and Fatema, K. Analysis of sociodemographic and clinical factors associated with hospitalized stroke patients of Bangladesh. Faridpur Med Coll J ; 2011; 6 : 19-23.

3. Hossain, M.Z., Ahmed, S.U., Sarder, M.H., Dasgupta, R., Das, A., Sarker R.N. et al.. Analysis of risk factors associated with stroke in young adults: a prospective study. J Dhaka Med Coll. 2009;18: 95-99

4. Hutchinson EC, Acheson EJ. Stroke: Natural History, Pathology and Surgical Treatment. Philadelphia, Pa: WB Saunders Co; 1975; 138-77.

5. Terent A. Survival after stroke and transient ischemic attacks during the 1970 s and 1980 s. Stroke. 1989;20:1320-26.

6. Sacco RL, Wolf PA, Kannel WB, McNamara PM. Survival and recurrence following stroke: the Framingham Study. Stroke. 1982; 13:290-95.

7. Hier DB, Foulkes MA, Swiontoniowski M, Sacco RL, Gorelick PB, Mohr JP, Price TR, Wolf PA. Stroke recurrence within 2 years after ischemic infarction. Stroke. 1991;22:155-61.

8. Bamford J, Sandercock PS, Jones L, Warlow C. The natural history of lacunar infarction: the Oxfordshire Community Stroke Project. Stroke. 1987;18:545-51.

9. Whisnant JP, Fitzgibbons JP, Kurland LT, Sayre GP. Natural history of stroke in Rochester, Minnesota, 1945 through 1954. Stroke. 1971;2:II-22.

10. Nadeau SE. Stroke. Geriatric Med. 1989;73:1351-1369. 
11. Wolf PA, Kannel WB, McGee DL, Meeks SL, Bharucha NE, McNamara PM. Duration of atrial fibrillation and imminence of stroke: the Framingham Study. Stroke. 1983;15:664-67.

12. Sacco RL, Foulkes MA, Mohr JP, Wolf PA, Hier DB, Price TR. Determinants of early recurrence of cerebral infarction: the Stroke Data Bank. Stroke. 1989;20:983-89.

13 Sage JI, Van Uitert RL. Risk of recurrent stroke in patients with atrial fibrillation and non-valvular heart disease. Stroke. 1983;14: 537-40.

14. Olsson $\mathrm{T}$, Viitanen $\mathrm{M}$, Asplund $\mathrm{K}$, Eriksson $\mathrm{S}$, Hagg E. Prognosis after stroke in diabetic patients: a controlled prospective study. Diabetologia. 1990;3:244-249.

15. Viitanen M, Eriksson S, Asplund K. Risk of recurrent stroke, myocardial infarction and epilepsy during long term follow-up after stroke. Acta Neuml. 1988;28:227-31.

16 Toni D, Fiorelli M, Gentile M, Bastianello S, Sacchetti ML, Argentino C, Pozzilli C, Fieschi C. Deteriorating neurological deficit secondary to acute ischemic stroke: a study on predictability, pathogenesis, and prognosis. Arch Neurol. 1995;52:670-75.

17 Goldstein LB, Perry A. Early recurrent ischemic stroke: a case-control study. Stroke. 1992;23:1010-13.

18. Broderick JP, Phillips SJ, O'Fallon WM, Fryc $\mathrm{RL}$, Whisnant JP. Relationship of cardiac disease to stroke occurrence, recurrence, and mortality. Stroke. 1992;23:1250-56.

19. Kazunori Toyoda 1, Yasushi Okada, Shotai Kobayashi et al Early Recurrence of Ischemic Stroke in Japanese Patients: The Japan Standard Stroke Registry Study . Cerebrovasc Dis . 2007; 24(2-3):289-95.

20. Joan T Moroney, Emilia Bagiella, Myunghee C Paik, Ralph L Sacco, David W Desmond et al . risk factors for early recurrence after ischemic stroke. Stroke . 1998; 29:2118-24.

21. John Murn, Martin Dennis. John Bamford, Peter Sandercock, Derick Wade, Charles Warlow et al. Long term risk of recurrent stroke after a first ever stroke project. Stroke. 1994; 25(2)333-37.
22. Jing Zhang, Ping Zhu, Bingqing Liu, Qiang Yao, Ke Yan, Qianwen et al Time to recurrence after first-ever ischaemic stroke within 3 years and its risk factors in Chinese population: a prospective cohort study. BMJ Open 2019;9:03208

23. Wang $\mathrm{Y}, \mathrm{Xu} \mathrm{J}$, Zhao $\mathrm{X}$, et al. Association of hypertension with stroke recurrence depends on ischemic stroke subtype. Stroke 2013;44:1232-37.

24. Hardie K, Hankey GJ, Jamrozik K, et al. TenYear risk of first recurrent stroke and disability after first-ever stroke in the Perth community stroke study. Stroke 2004;35:731-35.

25. Feng W, Hendry RM, Adams RJ. Risk of recurrent stroke, myocardial infarction, or death in hospitalized stroke patients. Neurology 2010;74:588-93.

26. Alter M, Sobel E, McCoy R, Francis ME, Davanipour Z, Shofer F, Levitt LP, Meehan EF. Stroke in the Lehigh Valley: risk factors for recurrent stroke. Neurology. 1987;37: 503-07.

27. T Leoo, A Lindgren, J Petersson, M von Arbinet et al. Risk Factors and Treatment at Recurrent Stroke Onset: Results From the Recurrent Stroke Quality and Epidemiology (RESQUE) Study Cerebrovasc Dis 2008;25(3):254-60.

28. Jingjing Chen, shun Li,Huaiming Wang, Yi Xie, Pengfei $\mathrm{Xu}$ et al. Impact of Smoking Status on Stroke Recurrence. Journal of American Heart association. 2019; 8:e 011696.

29. Jong-Won Chung, Beom Joon Kim , MoonKu Han, Kyusik Kang, Jong-Moo Park et al. Family History and Risk of Recurrent Stroke . Stroke, 2016, 47(8): 1990-96.

30. Keon joo, Beomjoonkim,Moon ko Han , joontaekim et al Effect of heart rate on stroke recurrence and mortality in acute ischaemic stroke with atrial fibrillation.. Stroke. 2020: 51: 162-69.

31. COX DR. Regression models and life-tables. / R Statist Soc. 1970; 34:187-20. 